\title{
Efeito da porosidade nas propriedades mecânicas de uma alumina de elevada pureza
}

\author{
(Effect of porosity on mechanical properties \\ of a high purity alumina)
}

\author{
H. N. Yoshimura ${ }^{1}$, A. L. Molisani ${ }^{1}$, G. R. Siqueira ${ }^{1}$, \\ A. C. de Camargo ${ }^{1}$, N. E. Narita ${ }^{1}$, P. F. Cesar ${ }^{2}$, H. Goldenstein ${ }^{3}$ \\ ${ }^{1}$ Instituto de Pesquisas Tecnológicas do Estado de São Paulo S.A. - IPT \\ Av. Prof. Almeida Prado 532, S. Paulo, SP 05508-901 \\ ${ }^{2}$ Faculdade de Odontologia da Universidade de S. Paulo \\ Av. Prof. Lineu Prestes 2227, S. Paulo, SP 05508-000 \\ ${ }^{3}$ Escola Politécnica da Universidade de S. Paulo \\ Av. Prof. Mello Moraes 2463, S. Paulo, SP 05508-900
}

\begin{abstract}
Resumo
Uma alumina de elevada pureza dopada com $\mathrm{MgO}$ foi sinterizada entre 1300 e $1700{ }^{\circ} \mathrm{C}$ para preparação de corpos com diferentes porosidades. Foram determinadas a resistência à flexão em quatro pontos, a tenacidade à fratura pelo método SEVNB, a dureza Vickers, as velocidades sônicas (longitudinal e transversal) e as constantes elásticas ( $\mathrm{v}, \mathrm{E}, \mathrm{G}$ e K) pelo método do pulso-eco ultrassônico. Os resultados foram comparados com os modelos baseados em concentração de tensão (CT) e modelos baseados na área sólida mínima (ASM). A porosidade das amostras variou entre 0,8\% e 35\%. Em geral, as propriedades diminuíram com o aumento da porosidade, sendo que a diminuição foi menos acentuada nas velocidades sônicas e mais acentuada na dureza. $\mathrm{O}$ coeficiente de Poisson só diminuiu em porosidade acima de 19\%. O modelo analítico (CT) que melhor se ajustou aos resultados dos módulos E e G foi o de Hashin-Rosen para configuração de poros cilíndricos alinhados transversalmente à tensão aplicada. A análise pelos modelos de ASM indicou que, até 19\% de porosidade, o modelo de poros esféricos em arranjo cúbico foi predominante e, acima desta porosidade, atuou também o modelo de partículas esféricas em arranjo cúbico.

Palavras-chave: alumina, propriedades mecânicas, porosidade, sinterização.
\end{abstract}

\begin{abstract}
A high purity alumina doped with $\mathrm{MgO}$ was sintered between 1300 and $170{ }^{\circ} \mathrm{C}$ in order to prepare samples with different porosities. The following properties were determined: four-point flexural strength, fracture toughness, by SEVNB method, Vickers hardness, (transversal and longitudinal) sonic velocities, and elastic constant ( $v, E, G$ e K), by ultrasonic pulse-echo method. The results were compared with models based on stress concentration (SC) and models based on minimum solid area (MSA). The porosity of the samples varied between $0.8 \%$ and 35\%. Generally, the properties lowered with increasing porosity. This lowering was weaker in sonic velocities and stronger in hardness. The Poisson's ratio lowered only above 19\% porosity. The analytical model (SC) which best fitted the results of $E$ and $G$ moduli was the Hashin-Rosen model for cylindrical pores aligned transversally to the applied stress. Analysis by ASM models indicated that, until 19\% porosity, the model for spherical pores in cubic stacking was predominant and, above this porosity, the model for spherical particles in cubic stacking also acted.
\end{abstract}

Keywords: alumina, mechanical properties, porosity, sintering.

\section{INTRODUÇÃO}

$\mathrm{O}$ efeito da porosidade nas propriedades dos materiais cerâmicos tem sido estudado a longa data (pelo menos desde a década de 1950), pois a principal rota de processamento destes materiais é a tecnologia do pó, que geralmente resulta em uma fração de poros residual involuntária, em decorrência da limitação do processo de densificação na sinterização ou da otimização tecnológica de custo/benefício, ou proposital, quando se deseja obter materiais porosos para aplicação como suportes catalíticos ou filtros. Apesar dos diversos estudos, há muito ainda a se compreender sobre o efeito da porosidade nas propriedades físicas das cerâmicas e de outros materiais [1]. A possibilidade de se controlar os poros para controle 
e otimização das propriedades é que impulsiona os estudos para compreensão da sua relação, o que necessariamente passa pelo modelamento do(s) mecanismo(s) envolvido(s) nesta relação.

Dentre as propriedades mecânicas, o efeito da porosidade tem sido estudado principalmente no módulo de elasticidade e na resistência à flexão. Há duas principais vertentes de modelos que prevêem este efeito $[1,2]$ : modelos baseados em geometrias ou área da seção transversal que suporta o carregamento; e modelos baseados em micro-mecanismos, que envolvem a concentração de tensão ao redor dos poros.

As Eqs. A a H (Tab. I) representam os modelos baseados na área de carregamento e são empíricas ou semi-empíricas, pois os parâmetros das equações são obtidos pelos ajustes nos resultados experimentais. A interpretação dos ajustes geralmente é realizada com base em uma geometria de distribuição de poros ou de partículas sólidas. A regra das misturas (modelo de Voight), que é uma forma particular da equação linear (Eq. A) supondo b=1, relaciona a propriedade diretamente com a fração volumétrica, ou fração em área média da seção, da parte sólida. Entretanto, a maioria das propriedades mecânicas apresenta diminuição mais acentuada $(b>1)$ com a porosidade do que a prevista pela regra das misturas. Diversos modelos de fração em área efetiva ao carregamento, que tem sido denominado por Rice $[2,7]$ de área sólida mínima (ASM), têm sido propostos com diferentes geometrias de poros, partículas sólidas e/ou carregamento. A Fig. 1 apresenta alguns destes modelos representados em um gráfico semi-log. As curvas das propriedades em função da porosidade plotadas em gráfico

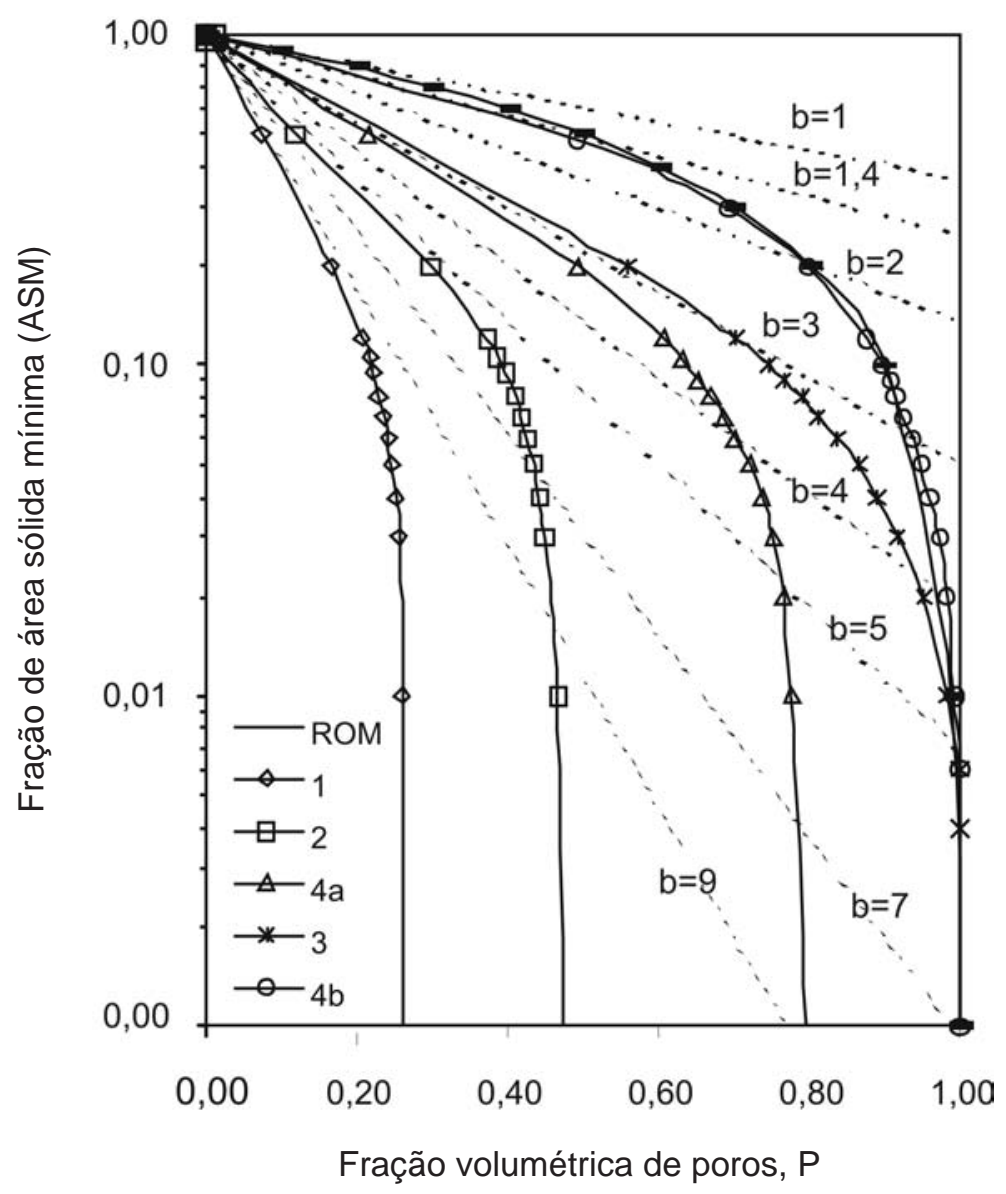

Figura 1: Áreas sólidas mínimas em função da fração volumétrica de poros (P) calculadas para empilhamentos uniformes de: partículas esféricas em empilhamento romboédrico (curva 1), partículas esféricas em empilhamento cúbico (curva 2), poros esféricos em empilhamento cúbico (curva 3), poros cilíndricos em empilhamento cúbico alinhados transversalmente à tensão aplicada (curva 4a) e poros cilíndricos em empilhamento cúbico alinhados paralelamente à tensão aplicada (curva 4b) (curvas baseadas em [1, 7]). A curva ROM indica a regra das misturas. As curvas exponenciais, exp(-bP), são apresentadas em linhas tracejadas com diferentes valores de b.

[Figure 1: Minimum solid areas versus volume fraction of pores $(P)$ calculated for uniform stackings of: spherical particles in rhombohedral stacking (curve 1), spherical particles in cubic stacking (curve 2), spherical pores in cubic stacking (curve 3), cylindrical pores in cubic stacking aligned transversal to applied stress (curve 4a), and cylindrical pores in cubic stacking aligned parallel to applied stress (curve 4b) (based on $[1,7])$. The curve ROM indicates the rule of mixture. Exponential curves, exp (-bP), are plotted as dashed lines with different $b$ values.] 
similar possibilita a correlação com os modelos de ASM. Possibilita também correlacionar mudanças de modelo com a variação da porosidade devido às mudanças de geometria dos poros ou das partículas sólidas, como ocorre na evolução microestrutural durante a sinterização de pós [1]. A característica básica destes modelos é que a propriedade decai inicialmente de forma aproximadamente linear (em gráfico semi-log) e depois apresenta rápido decréscimo levando a um valor zero em uma porosidade crítica, Pc, que é o limite de percolação das partículas [7]. No caso de partículas empilhadas, as áreas sólidas mínimas são as áreas de ligação entre elas e, no caso de estruturas celulares, são as áreas transversais das paredes das células [1]. A parte inicial dos modelos de ASM pode ser aproximada com uma equação exponencial (Eq. C) com um dado valor de b. Rice [7] observou que os dados de literatura para as propriedades mecânicas e condutividades térmica e elétrica de diferentes cerâmicas apresentaram valor médio de b de cerca de 4. Este valor seria de se esperar, pois representaria a média de todos os modelos de ASM [7]. Observou também que o valor de $\mathrm{b}$ depende dos métodos de consolidação dos materiais cerâmicos: valores baixos de b para cerâmicas conformadas por extrusão e valores elevados para cerâmicas prensadas a quente estariam relacionados com as características dos poros [7]. Os modelos de ASM são aplicáveis às propriedades que são determinadas pela transmissão de tensão ou por

Tabela I - Equações semi-empíricas (A a H) e analíticas (I a N) de constantes elásticas em função da porosidade P [2-6]. M pode ser E, G ou K (módulos de Young, de cisalhamento e volumétrico, respectivamente). O subscrito 0 indica a propriedade do material sem poros. Os valores de $b, b_{1}, b_{2}, A, B$, Pc e $n$ das equações semi-empíricas (Eq. A a G) são determinados pelo ajuste nos resultados experimentais. $\rho$ e $v$ são, respectivamente, a densidade e o coeficiente de Poisson. O subscrito v indica a propriedade do corpo-verde.

[Table I - Semi-empirical (A to H) and analytical ( I a N) equations for elastic constants in function of porosity P [2-6]. M is $E, G$, or $K$ (Young, shear, and bulk moduli, respectively). The subscript 0 indicates the property of the material without pores. The values of $b, b_{1}, b_{2}, A, B, P c$, and $n$ of the semi-empirical equations (Eq. A to $G$ ) are determined by fitting to the experimental results. $\rho$ and $v$ are, respectively, the density and the Poisson's ratio. The subscript $v$ indicates the property of the green body.]

\begin{tabular}{|c|c|c|}
\hline Autor (ano) & Equações & \\
\hline--- & $\mathrm{M}=\mathrm{M}_{0}(1-\mathrm{bP})$ & (A) \\
\hline--- & $\mathrm{M}=\mathrm{M}_{0}\left(1-\mathrm{b}_{1} \mathrm{P}+1-\mathrm{b}_{2} \mathrm{P}^{2}\right)$ & (B) \\
\hline \multicolumn{3}{|l|}{ Knudsen (1959); } \\
\hline Spriggs (1961) & $\mathrm{M}=\mathrm{M}_{\mathrm{o}} \exp (-\mathrm{bP})$ & $(\mathrm{C})$ \\
\hline Hasselman (1962) & $\mathrm{E}=\mathrm{E}_{0}\{1-\mathrm{AP} /[1+(\mathrm{A}-1) \mathrm{P}]\}=\mathrm{E}_{0}(1-\mathrm{P}) /(1+\mathrm{bP})$ & (D) \\
\hline Martin e Haynes (1971) & $\mathrm{E}=\mathrm{E}_{0}\left(1-\mathrm{bP}^{2 / 3}\right)$ & (E) \\
\hline Wang (1984) & $\mathrm{E}=\mathrm{E}_{0} \exp \left(-\mathrm{b}_{1} \mathrm{P}+-\mathrm{b}_{2} \mathrm{P}^{2}\right)$ & $(\mathrm{F})$ \\
\hline Phani e Niyogi (1987) & $\mathrm{E}=\mathrm{E}_{0}\left(1-\mathrm{P} / \mathrm{P}_{\mathrm{c}}\right)^{\mathrm{n}}$ & $(G)$ \\
\hline Lam et al. (1994) & $M=M_{0}\left(\rho-\rho_{v}\right) /\left(1-\rho_{v}\right)=$ Mo $\left(1-P / P_{v}\right)$ & $(\mathrm{H})$ \\
\hline Dewey (1947); & $\mathrm{G}=\mathrm{G}_{0}\left[1-15 \mathrm{P}\left(1-\mathrm{v}_{0}\right) /\left(7-5 \mathrm{v}_{0}\right)\right]$ & (I.1) \\
\hline Hashin (1962) & $\mathrm{K}=\mathrm{K}_{0}\left[1-3\left(1-\mathrm{v}_{0}\right) \mathrm{P} /\left(2-4 \mathrm{v}_{0}\right)\right]$ & $(\mathrm{I} .2)$ \\
\hline \multirow[t]{2}{*}{ Mackenzie (1950) } & $\mathrm{G}=\mathrm{G}_{0}\left[1-5 \mathrm{P}\left(3 \mathrm{~K}_{0}+4 \mathrm{G}_{0}\right) /\left(9 \mathrm{~K}_{0}+8 \mathrm{G}_{0}\right)-\mathrm{AP}^{2}\right.$ & (J.1) \\
\hline & $\mathrm{K}=\mathrm{K}_{0}\left\{(1-\mathrm{P})^{-1}+3 \mathrm{PK}_{0} /\left[4 \mathrm{G}_{0}(1-\mathrm{P})\right]+\mathrm{BP}^{3}\right\}^{-1}$ & $(\mathrm{~J} .2)$ \\
\hline \multirow[t]{2}{*}{ Kerner (1952) } & $\mathrm{G}=\mathrm{G}_{0}(1-\mathrm{P})\left(7-5 \mathrm{v}_{0}\right) /\left[\mathrm{P}\left(8-10 \mathrm{v}_{0}\right)+7-5 \mathrm{v}_{0}\right]$ & $(\mathrm{K} .1)$ \\
\hline & $\mathrm{K}=4 \mathrm{~K}_{0} \mathrm{G}_{0}(1-\mathrm{P}) /\left(4 \mathrm{G}_{0}+3 \mathrm{PK}_{0}\right)$ & $(\mathrm{K} .2)$ \\
\hline \multirow[t]{3}{*}{ Hashin (1962) } & $\mathrm{E}=\mathrm{E}_{0}(1-\mathrm{P}) /\left(1+\mathrm{k}_{1} \mathrm{P}\right) \mathrm{k}_{1}=\left(1+\mathrm{v}_{0}\right)\left(13-15 \mathrm{v}_{0}\right) /\left[2\left(7-5 \mathrm{v}_{0}\right)\right]$ & (L.1) \\
\hline & $\mathrm{G}=\mathrm{G}_{0}(1-\mathrm{P}) /\left(1+\mathrm{k}_{2} \mathrm{P}\right) \mathrm{k}_{2}=2\left(4-5 \mathrm{v}_{0}\right) /\left(7-5 \mathrm{v}_{0}\right)$ & (L.2) \\
\hline & $\mathrm{K}=\mathrm{K}_{0}(1-\mathrm{P}) /\left(1+\mathrm{k}_{3} \mathrm{P}\right) \mathrm{k}_{3}=2\left(1+\mathrm{v}_{0}\right) /\left[2\left(1-2 \mathrm{v}_{0}\right)\right.$ & (L.3) \\
\hline \multirow[t]{2}{*}{ Hashin e Rosen (1964) } & $\mathrm{E}=\mathrm{E}_{0}(1-\mathrm{P})$ & (M.1) \\
\hline & $\mathrm{G}=\mathrm{G}_{0}(1-\mathrm{P}) /(1+\mathrm{P})$ & (M.2) \\
\hline \multirow[t]{3}{*}{ Hashin e Rosen (1964) } & $\mathrm{E}=4 \mathrm{GK}(\mathrm{K}+\psi \mathrm{G}) \psi=1+\mathrm{Kv}_{0}^{2} /\left[\mathrm{E}_{0}\left(1-\mathrm{P}_{0}\right]\right.$ & (N.1) \\
\hline & $\mathrm{G}=\mathrm{G}_{0}\left\{1-4 \mathrm{P}\left(1-\mathrm{v}_{0}\right) /\left[1+2 \mathrm{P}\left(1-2 \mathrm{v}_{0}\right)\right]\left(\right.\right.$ para $1^{\mathrm{a}}$ ordem de $\left.\mathrm{P}\right)$ & (N.2) \\
\hline & $\mathrm{K}=2 \mathrm{v}_{0}\left(\mathrm{~K}_{0}+\mathrm{G}_{0}{ }^{3}\right)(1-\mathrm{P}) /\left(\mathrm{P}+2 \mathrm{v}_{0}\right)$ & (N.3) \\
\hline
\end{tabular}


fluxos condutivos, como as propriedades mecânicas e as condutividades térmica e elétrica, mas não são aplicáveis a propriedades que dependem da massa, como capacidade calorífica, índice de refração e constante dielétrica; nestes casos, as propriedades seguem a regra das misturas [7].

A equação exponencial (Eq. C) tem sido a mais utilizada para os ajustes das propriedades em função da porosidade [2]. Rice [1] defende a utilização desta equação, pois o parâmetro b (Eq. C), na faixa de baixa porosidade, pode indicar o tipo de empacotamento de partículas e a estrutura dos poros do modelo de área sólida mínima (Fig. 1).

Dean e Lopez [3] ajustaram, a diversos dados de literatura de módulos de elasticidade de diferentes cerâmicas contendo poros, as equações linear (Eq. A), exponencial (Eq. C), de Hasselman (Eq. D) e de Martin e Haynes (Eq. E). Eles observaram que, em geral, a equação linear apresentou os melhores ajustes aos valores experimentais entre as equações testadas.

As Eqs. A a $\mathrm{F}$ geralmente são válidas para uma faixa relativamente limitada de poros. A equação de Phani e Niyogi (Eq. G) pode ser aplicada em uma larga faixa de porosidade e prevê um valor de Pc no qual o módulo de elasticidade tornase zero. O valor de Pc está relacionado com a geometria de empacotamento das partículas [4]. Phani e Niyogi [8] testaram a Eq. G para diversos óxidos de terras raras e compararamna com as equações linear (Eq. A), polinomial (Eq. B), exponencial (Eq. C), de Hasselman (Eq. D) e de Wang (Eq. F). Eles observaram melhor ajuste da Eq. G para seis óxidos (de Sm, Lu, Yb, Dy, Er e Sc), mas para o óxido de Y, o melhor ajuste foi o polinômio de $2^{\circ}$ grau (Eq. B).

Lam et al. [5] observaram que o módulo de Young e a tenacidade à fratura apresentaram relação linear com a fração (ou grau) de densificação, termo $\left(\rho-\rho_{\mathrm{v}}\right) /\left(1-\rho_{\mathrm{v}}\right)$ da Eq. H, para uma alumina preparada com duas diferentes densidades a verde $\left(\rho_{\mathrm{v}}\right)$ e sinterizadas em diferentes temperaturas. Observaram também a semelhança com a equação de Phani e Niyogi (Eq. G), supondo $\mathrm{Pc}=\mathrm{Pv}$ e $n=1$. Na derivação da Eq. H, Lam et al. [5] supuseram que o módulo tendia a zero quando $\rho \rightarrow \rho_{v}$.

Nanjangud et al. [9] notaram que a Eq. H não se correlacionou bem aos valores experimentais de módulo E na faixa de baixo grau de densificação (até cerca de $20 \%$ ). Observaram que a resistência à flexão e o módulo E aumentaram rapidamente no estágio inicial da sinterização com mínima densificação. Propuseram uma correção na Eq. $\mathrm{H}$ pela introdução do módulo $\mathrm{E}^{\prime}$ de início de densificação para $\rho \rightarrow \rho_{v}$.

As Eqs. I a N (Tabela I) representam os modelos analíticos baseados na concentração de tensão prevendo os módulos de elasticidade. As Eqs. I a L são válidas para concentrações limitadas de poros esféricos. As Eqs. M e N consideram concentrações limitadas de poros cilíndricos alinhados, sendo a direção de carregamento paralela ou perpendicular à direção do eixo do poro cilíndrico para as Eqs. M e N, respectivamente. Note que a Eq. M1 é igual à equação da regra das misturas. Em geral, as Eqs. I a N (Tabela I) consideram o coeficiente de Poisson, $v$, invariante e igual ao do corpo sem poros. Budiansky em 1970 (apud [2]) propôs equações similares às propostas por Dewey e por Hashin (Eq. I), mas com o coeficiente $v$ variável com a porosidade. Rice [2], supondo que $v$ diminuía conforme a regra das misturas, notou que as equações de Budiansky e de Dewey foram próximas para os módulos de Young, E, e de cisalhamento, G, mas a primeira previu valores maiores de módulo volumétrico, K, para porosidade acima de $20 \%$.

Rice $[10,11]$ questiona a aplicabilidade destes modelos analíticos, pois considera que não há base fundamental para que as propriedades elásticas sejam determinadas pela concentração de tensão ao redor dos poros.

Há diversos estudos experimentais [9, 12-17] mostrando o efeito da porosidade nos módulos de elasticidade e na resistência à flexão, entretanto há poucos trabalhos [5, 18-20] relativos à tenacidade à fratura e, principalmente, dureza. Não foram observados, na literatura, trabalhos que apresentassem simultaneamente as diversas determinações de propriedades realizadas neste trabalho, com exceção das revisões de Rice $[1,2,7]$. Nestes casos, porém, a comparação entre os resultados de diferentes fontes fica limitada às diferenças de natureza, pureza e processamento da cerâmica. Neste trabalho, foram verificadas as propriedades de velocidades sônicas, constantes elásticas (coeficiente de Poisson e módulos de elasticidade), resistência à flexão, tenacidade à fratura e dureza Vickers de uma alumina de elevada pureza dopada com $\mathrm{MgO}$ sinterizada em diferentes temperaturas. Os resultados destas propriedades em função da porosidade foram avaliados com os modelos propostos na literatura.

\section{MATERIAIS E MÉTODOS}

Foi utilizado um pó atomizado de alumina comercial de elevada pureza com 500 ppm de MgO (AKS 3030 NA, Sumitomo). Os corpos-verdes foram preparados por prensagem uniaxial a $200 \mathrm{MPa}$ utilizando uma matriz de aço com seção da cavidade de 5,1 x $60 \mathrm{~mm}^{2}$. Fixou-se a massa de cada corpo-verde em 2,58 g, o que resultou em corpos com altura de 3,8 mm. Os corpos-verdes (pelo menos 30 para cada condição) foram sinterizados ao ar em um forno elétrico (FD41, Yamato) por $1 \mathrm{~h}$ nas temperaturas de 1300, $1350,1400,1450,1500,1600$ e $1700{ }^{\circ} \mathrm{C}$. No aquecimento foi realizado um patamar intermediário por $1 \mathrm{~h}$ a $500{ }^{\circ} \mathrm{C}$ para retirada do ligante. A taxa de aquecimento foi de $10{ }^{\circ} \mathrm{C} / \mathrm{min}$ e a taxa de resfriamento foi de $30^{\circ} \mathrm{C} / \mathrm{min}$.

A densidade do corpo-verde foi determinada pelo método geométrico e a densidade do corpo sinterizado pelo método de Arquimedes. Para os corpos sinterizados contendo poros fechados, os corpos foram imersos diretamente na água e, para os corpos com poros abertos (sinterizados a $1450^{\circ} \mathrm{C}$ ou abaixo), os corpos foram recobertos com uma camada de esmalte (para pintar unhas) para a medição da massa imersa, sendo a densidade calculada por: 


$$
G=\rho \cdot V_{T}^{2}
$$

$$
\rho=m_{a, s}\left(\frac{m_{a, c}-\left(m_{i, c}-m_{i, f}\right)}{\rho_{H 2 O, T}}-\frac{m_{a, c}-m_{a, s}}{\rho_{\text {esmalte }}}\right)^{-1}
$$

onde, m é a massa (os subscritos a e i indicam medição ao ar e imersa, respectivamente, e os subscritos c, s e f indicam corpo com e sem camada de esmalte e fio de sustentação, respectivamente), $\rho_{\mathrm{H} 20, \mathrm{~T}}$ é a densidade da água na temperatura ambiente T e $\rho_{\text {esmalte }}$ é a densidade do esmalte. Determinouse a densidade do esmalte utilizando a metodologia acima e a Eq. O utilizando um corpo sem poros (vidro), cuja densidade foi pré-determinada por imersão direta. O esmalte foi retirado pela imersão dos corpos em um béquer contendo acetona sob agitação com ultrassom.

Após a determinação da densidade, os corpos sinterizados (semusinagem)foramensaiados para determinação daresistência à flexão em quatro pontos seguindo as recomendações da norma ASTM C-1161 [21]. Utilizou-se um suporte totalmente articulado com distâncias entre os apoios de 20 e 40 mm. Os ensaios foram realizados em um equipamento universal de ensaios mecânicos (Syntech 5G, MTS) de capacidade de 2,5 ton utilizando uma célula de carga de $5000 \mathrm{~N}$ e velocidade da travessa de $0,5 \mathrm{~mm} / \mathrm{min}$. As dimensões da seção foram medidas com um paquímetro digital (Mitutoyo), próxima à superfície de fratura. Os demais ensaios foram realizados com as partes rompidas no ensaio de flexão.

As determinações das constantes elásticas foram realizadas pelo método do pulso-eco ultrassônico, segundo a norma JIS R 1602 [22]. Foram utilizados um aparelho emissor-receptor de pulso ultra-sônico de $200 \mathrm{MHz}$ (5900 PR, Panametrics), transdutores de $20 \mathrm{MHz}$ de onda longitudinal (V208-RM, Panametrics) e de onda transversal (V222-BB-RM, Panametrics) e um acoplante (Couplant SWC, Panametrics), aplicado entre o corpo-de-prova e o transdutor. A medição do tempo de vôo do pulso ultrasônico foi realizada com um osciloscópio (TDS 1002, Tektronix). Os ensaios foram realizados na região próxima à extremidade original dos corpos sinterizados para se evitar a região próxima à fratura, onde a possibilidade de ocorrência de crescimento sub-crítico durante o ensaio de flexão é maior. A espessura da amostra foi medida com um paquímetro digital. As velocidades foram calculadas pela razão entre o dobro da espessura e o tempo de vôo. O coeficiente de Poisson (v) e os módulos de Young (E), de cisalhamento (G) e volumétrico $(K)$ foram calculados por:

$$
\begin{aligned}
& v=0,5 \cdot \frac{V_{L}^{2}-2 \cdot V_{T}^{2}}{V_{L}^{2}-V_{T}^{2}} \\
& E=\rho \cdot\left(\frac{3 \cdot V_{T}^{2} \cdot V_{L}^{2}-4 \cdot V_{T}^{4}}{V_{L}^{2}-V_{T}^{2}}\right)
\end{aligned}
$$

$$
\begin{aligned}
& G=\rho \cdot V_{T}^{2} \\
& K=\frac{\rho}{3}\left(3 \cdot V_{L}^{2}-4 \cdot V_{T}^{2}\right)
\end{aligned}
$$

onde, $\mathrm{V}_{\mathrm{L}}$ e $\mathrm{V}_{\mathrm{T}}$ são as velocidades das ondas longitudinal e transversal (ou cisalhamento), respectivamente, e $\rho$ é a densidade do corpo.

A tenacidade à fratura foi determinada pelo método SEVNB (single edge V-notched beam). Foram utilizadas as partes rompidas no ensaio de flexão com comprimento mínimo de $20 \mathrm{~mm}$. A partir de $10 \mathrm{~mm}$ da borda de cada uma destas partes, foi introduzido um entalhe com disco diamantado de espessura de cerca de 0,3 mm utilizando um equipamento específico para esta finalidade ("Fractometer Specimen Saw", modelo 4901, Terra Tek). O entalhe reto passante ao longo da seção foi introduzido a partir da face de cerca de $3 \mathrm{~mm}$ de espessura com profundidade de cerca de $40 \%$ da largura. Em seguida, a extremidade do entalhe foi desbastada utilizando uma lâmina de barbear e pasta de diamante de $15 \mu \mathrm{m}$ para formar o perfil "V" nesta extremidade. O corpo-de-prova preparado foi centralizado em um suporte rígido de flexão em três pontos com distância entre apoios de $16 \mathrm{~mm}$ com o entalhe voltado para o lado tensionado em tração. $\mathrm{O}$ ensaio foi realizado no equipamento de ensaios mecânicos utilizando uma célula de carga de 500 $\mathrm{N}$ e velocidade de avanço da travessa de $0,5 \mathrm{~mm} \cdot \mathrm{min}^{-1}$. Após este ensaio, foram medidas em três posições eqüidistantes, nas duas superfícies de fratura, o tamanho da pré-trinca utilizando um microscópio óptico (DMRXE, Leica). O valor da tenacidade à fratura, $\mathrm{K}_{\mathrm{Ic}}$, foi calculado por meio da equação da norma ASTM C 1421 [23] para o método SEPB (“single edge precracked beam”):

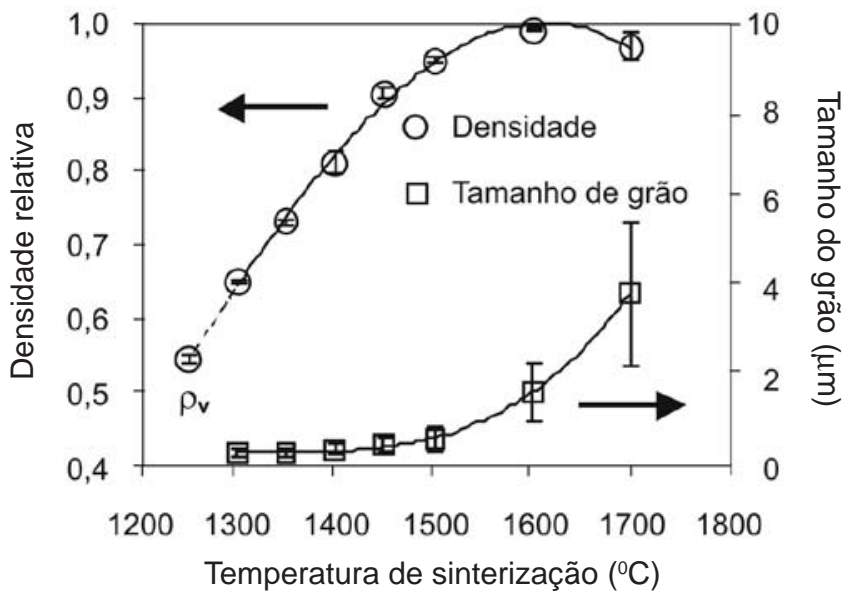

Figura 2: Densidade relativa e tamanho de grão das amostras sinterizadas entre 1300 e $1700{ }^{\circ} \mathrm{C}$. $\rho_{\mathrm{v}}$ é a densidade a verde. [Figure 2: Relative density and grain size of samples sintered between 1300 and $1700{ }^{\circ} \mathrm{C}$. $\rho_{v}$. is green density.] 

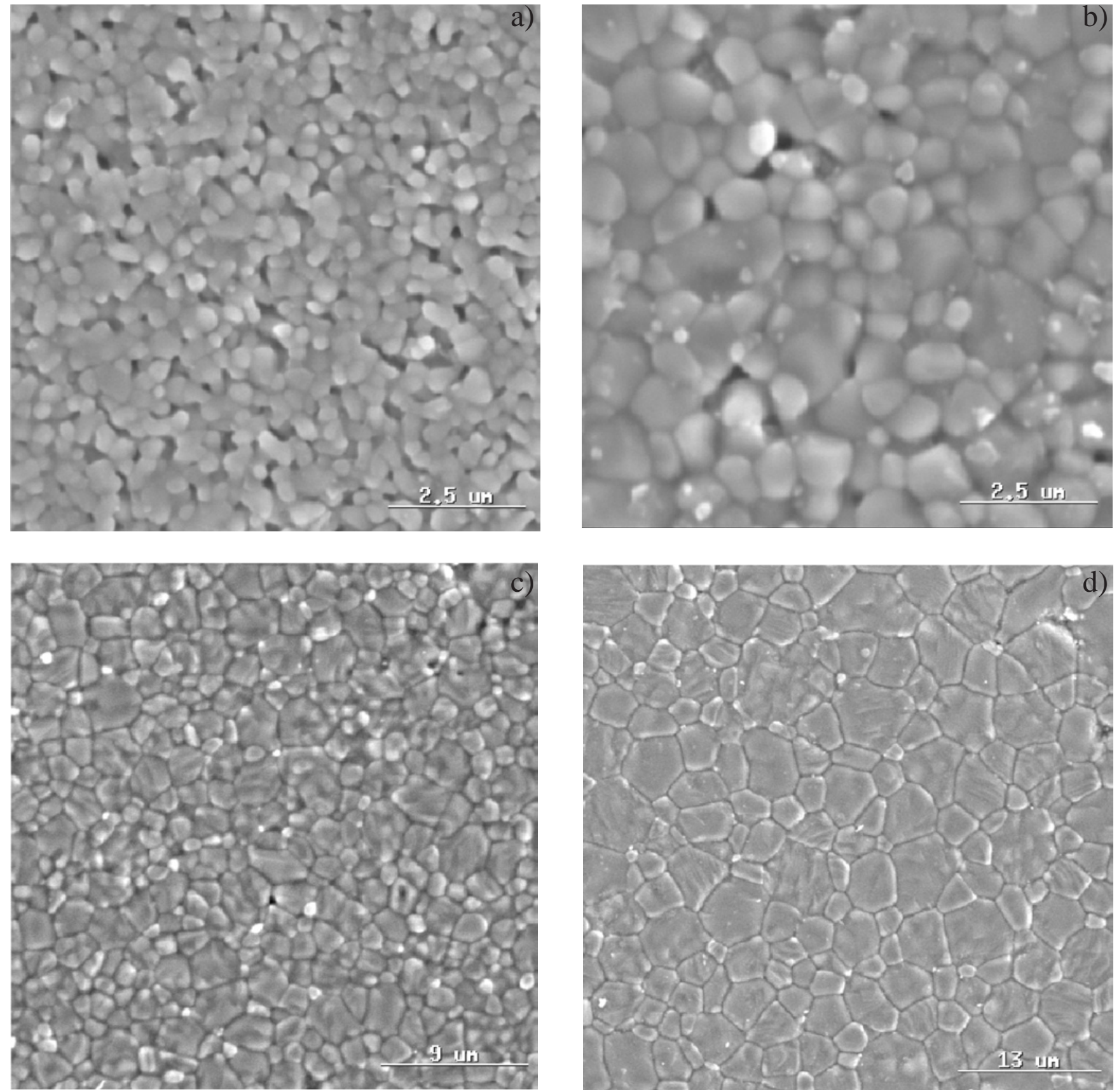

Figura 3: Micrografias de MEV das superfícies das amostras sinterizadas a $1350{ }^{\circ} \mathrm{C}$ (a), $1500{ }^{\circ} \mathrm{C}$ (b), $1600{ }^{\circ} \mathrm{C}$ (c) e $1700{ }^{\circ} \mathrm{C}$ (d). [Figure 3: SEM micrographs of the surfaces of the samples sintered at $1350{ }^{\circ} \mathrm{C}(\mathrm{a}), 1500{ }^{\circ} \mathrm{C}(\mathrm{b}), 1600{ }^{\circ} \mathrm{C}(\mathrm{c})$, and $1700{ }^{\circ} \mathrm{C}(\mathrm{d})$.]

$$
K_{I c}=g \cdot\left(\frac{P \cdot S}{B \cdot W^{3 / 2}}\right) \cdot\left[\frac{3(a / W)^{/ 2}}{2(1-a / W)^{3 / 2}}\right]
$$

onde, P é a força de ruptura, S é a distância entre os apoios, B e W são, respectivamente, a espessura e a largura do corpode-prova e a é o tamanho médio da pré-trinca. A função g, g(a/W), foi calculada conforme os valores de S/W [23].
A dureza foi determinada pelo método Vickers com carga de $1 \mathrm{kgf}$ em equipamento específico para este ensaio (MVK-H-3, Mitutoyo). Para a realização deste ensaio, cinco corpos de cada temperatura de sinterização foram polidos com diamante de até $1 \mu \mathrm{m}$. Na superfície polida de cada corpo foram realizadas duas indentações.

Foram realizadas análises microestruturais e fractográficas das amostras utilizando um microscópio eletrônico de varredura, MEV (JSM 6300, Jeol). O tamanho de grão foi determinado a partir de imagens obtidas das superfícies dos 
corpos sinterizados. As imagens foram ampliadas e os contornos de grão foram delineados em um programa de tratamento de imagens. As imagens dos contornos foram analisadas em um programa de análise de imagens (QWin,Leica) para determinação da área individual de cada seção de grão. O diâmetro equivalente desta área foi considerado como o tamanho do grão. Foram medidas pelo menos 200 seções de grão por amostra.

As análises comparativas dos resultados foram realizadas por meio da análise de variância e teste de Tukey com nível global de significância de $5 \%$. Os resultados das propriedades mecânicas em função da porosidade foram ajustados com as equações linear, de polinômio de $2^{\circ}$ grau e exponencial (Eq. A a C, respectivamente) para determinação dos valores na porosidade zero.

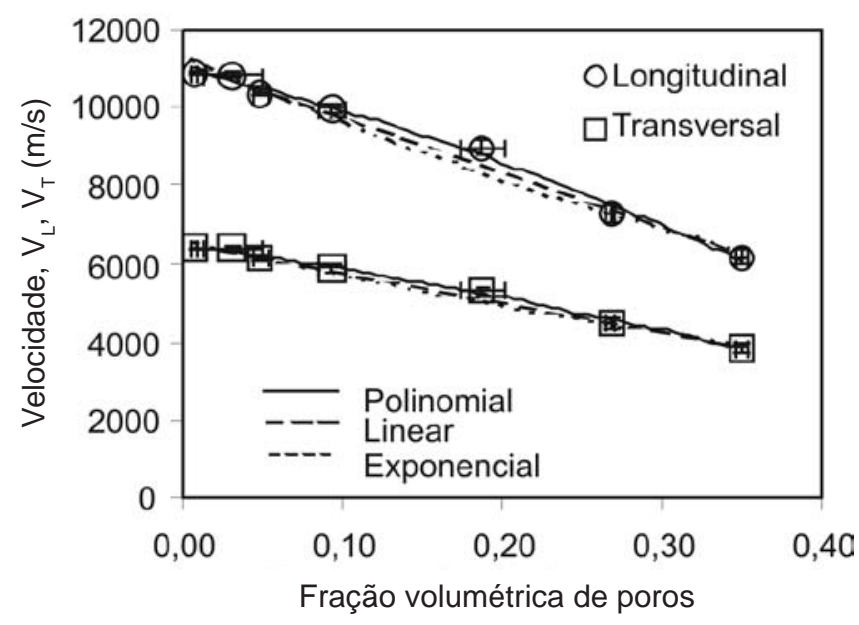

Figura 4: Resultados de velocidades sônicas longitudinal $\left(\mathrm{V}_{\mathrm{L}}\right)$ e transversal $\left(\mathrm{V}_{\mathrm{T}}\right)$ em função da porosidade.

[Figure 4: Results of longitudinal $\left(V_{L}\right)$ and transverse $\left(V_{T}\right)$ sonic velocities versus porosity. ]

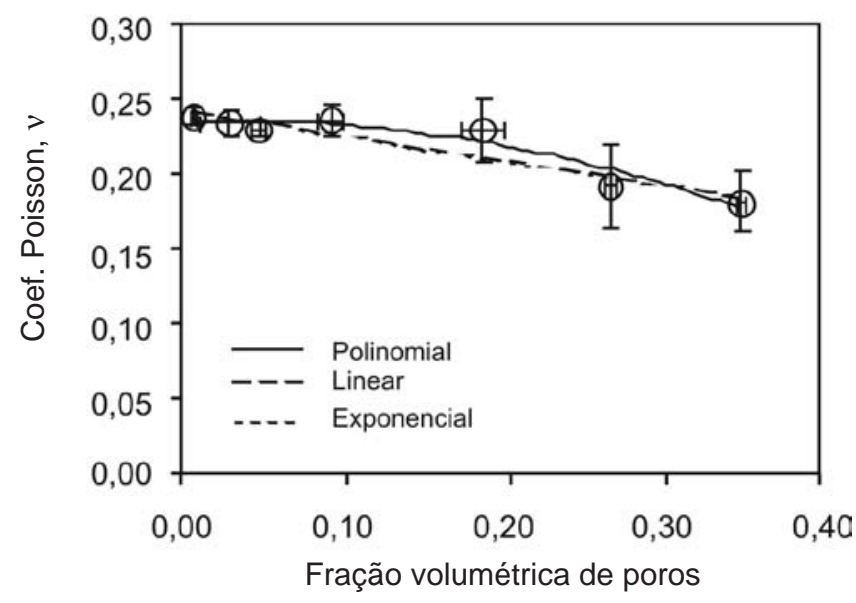

Figura 5: Resultados de coeficiente de Poisson (v) em função da porosidade.

[Figure 5: Results of Poisson's ratio (v) versus porosity.]

\section{RESULTADOS E DISCUSSÃO}

A densidade dos corpos-verdes foi de $(54,4 \pm 0,6) \%$ da densidade teórica da alumina $\left(3,986 \mathrm{~g} / \mathrm{cm}^{3}\right)$. A Fig. 2 apresenta os resultados de densidade relativa e tamanho de grão em função da temperatura de sinterização. A densidade aumentou rapidamente entre 1300 e $1500{ }^{\circ} \mathrm{C}$, alcançou valor máximo (99,2\% da densidade teórica) a $1600{ }^{\circ} \mathrm{C}$ e diminuiu a $1700{ }^{\circ} \mathrm{C}$. O tamanho de grão médio, que foi de $0,32 \mu \mathrm{m}$ a $1300{ }^{\circ} \mathrm{C}$, apresentou início de crescimento a $1400{ }^{\circ} \mathrm{C}$, mas aumento significativo foi observado a partir de $1500{ }^{\circ} \mathrm{C}$, alcançando $3,9 \mu \mathrm{m}$ a $1700{ }^{\circ} \mathrm{C}$ (Fig. 2). A Fig. 3 apresenta as microestruturas das amostras sinterizadas. A evolução microestrutural com o aumento da temperatura

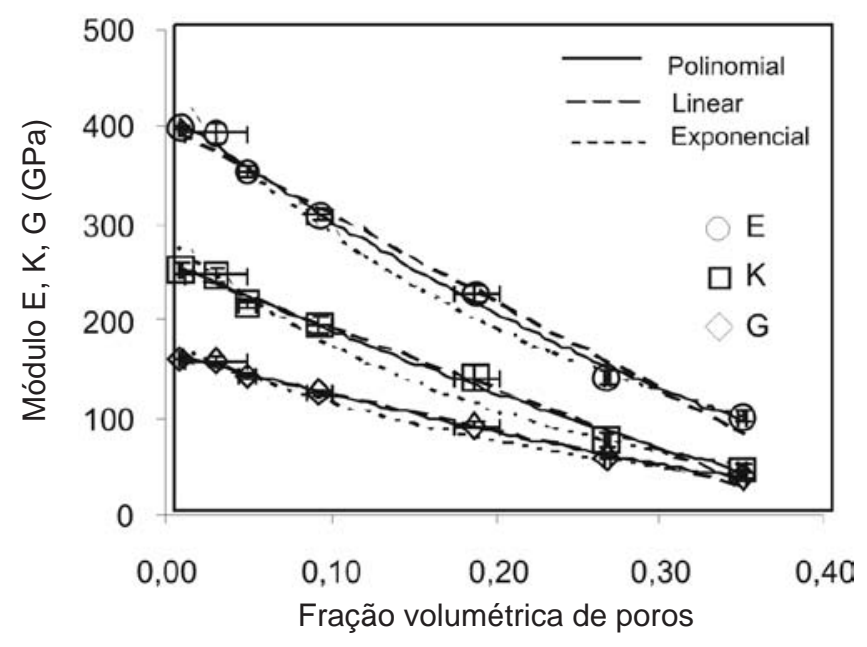

Figura 6: Resultados dos módulos de Young (E), de cisalhamento (G) e volumétrico (K) em função da porosidade.

[Figure 6: Results of Young's (E), shear $(G)$, and bulk $(K)$ moduli versus porosity.]

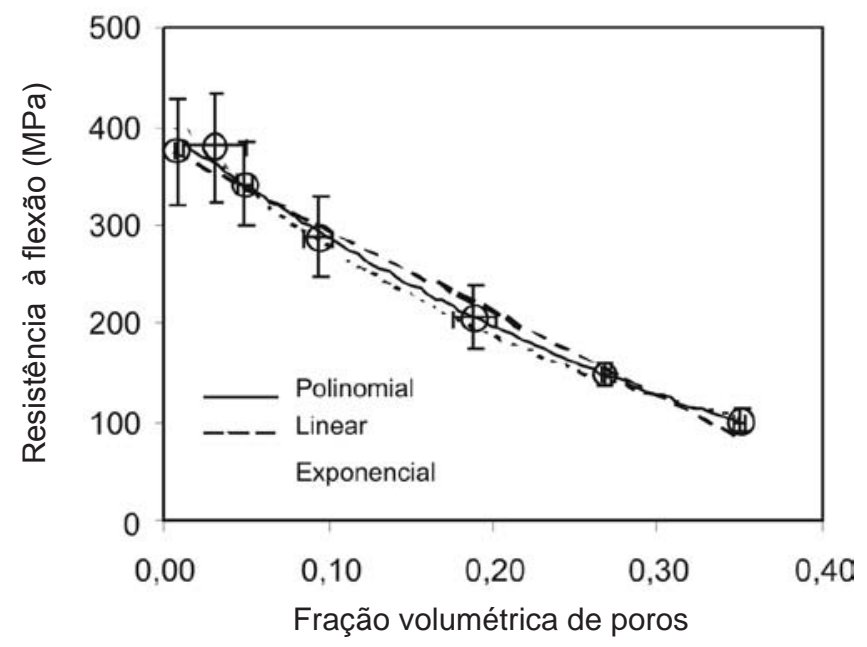

Figura 7: Resultados de resistência à flexão em quatro pontos $(\sigma)$ em função da porosidade.

[Figure 7: Results of four-point flexural strength ( $\sigma)$ versus porosity.] 


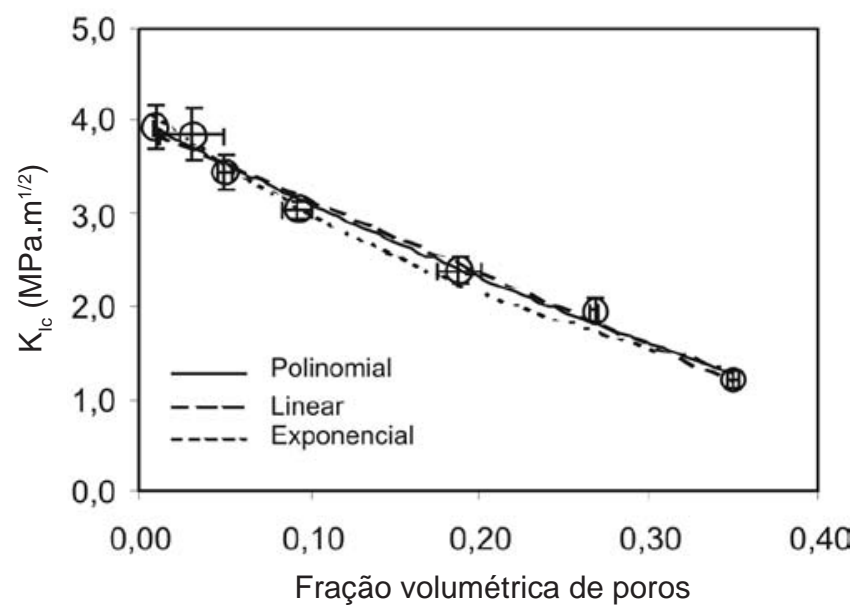

Figura 8: Resultados da tenacidade à fratura $\left(\mathrm{K}_{\mathrm{IC}}\right)$ em função da porosidade.

[Figure 8: Results of fracture toughness $\left(K_{\mathrm{IC}}\right)$ versus porosity.]

ocorreu gradualmente com o aumento da área de contato entre as partículas, diminuição da porosidade e crescimento de grão. Pelo ensaio de densidade, notou-se que os corpos apresentavam poros abertos até a temperatura de $1450{ }^{\circ} \mathrm{C}$. Não se observou ocorrência de crescimento anormal de grãos nos corpos sinterizados, mesmo a $1700{ }^{\circ} \mathrm{C}$ (Fig. 3d). Assim, a diminuição da densidade nesta temperatura (Fig. 2) não está associada com este fenômeno. Uma possível explicação é a ocorrência de crescimento e coalescimento de poros em altas temperaturas, que leva à diminuição da pressão interna dos gases (pelo aumento do raio do poro) e, como conseqüência, resulta em expansão do volume dos gases e dos poros, o que causa a diminuição da densidade [24, 25]. A pressão interna dos gases aprisionados nos poros fechados (principalmente $\mathrm{N}_{2}$ do ar) parece ter influência significativa, pois, em experiências realizadas em nosso laboratório, o pó utilizado pode ser sinterizado a $1850^{\circ} \mathrm{C}$ sob vácuo ou em atmosfera de hidrogênio e resultar em corpos com significativa transmissão luminosa, i.e., com baixa porosidade.

Os resultados das velocidades sônicas $\left(V_{L}\right.$ e $\left.V_{T}\right)$, dos módulos de elasticidade (E, G e K), da resistência à flexão, da tenacidade à fratura $\left(\mathrm{K}_{\mathrm{IC}}\right)$ e da dureza apresentaram tendências similares: os valores aumentaram com o aumento da temperatura de sinterização entre 1300 e $1600{ }^{\circ} \mathrm{C}$, enquanto os resultados a $1700{ }^{\circ} \mathrm{C}$ foram estatisticamente semelhantes aos de $1600^{\circ} \mathrm{C}$. Isto mostrou que a porosidade de até 3,1\% e o maior tamanho de grão $(3,9 \mu \mathrm{m})$ das amostras sinterizadas a $1700{ }^{\circ} \mathrm{C}$, em relação às amostras sinterizadas a $1600{ }^{\circ} \mathrm{C}$ (tamanho de grão de 1,7 $\mu \mathrm{m}$ ), pouco afetaram as propriedades mecânicas. Os resultados do coeficiente de Poisson apresentaram tendência diferente: os resultados de 1300 e $1350{ }^{\circ} \mathrm{C}$ foram semelhantes entre si e significativamente menores do que os das demais amostras, enquanto as amostras sinterizadas entre 1400 e $1700{ }^{\circ} \mathrm{C}$ apresentaram resultados estatisticamente semelhantes entre si.

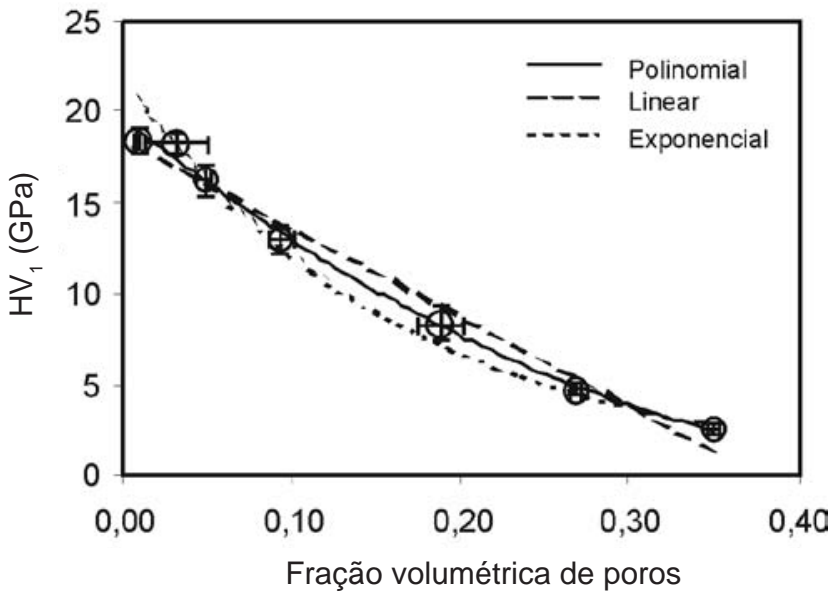

Figura 9: Resultados da dureza Vickers $\left(\mathrm{HV}_{1}\right)$ em função da porosidade.

[Figure 9: Results of Vickers hardness $\left(H V_{1}\right)$ versus porosity.]

As Figs. 4 a 9 apresentam os resultados das propriedades mecânicas em função da porosidade e a Tabela II apresenta os parâmetros das curvas (linear, polinomial e exponencial) ajustadas aos resultados. Em geral, o polinômio de $2^{\circ}$ grau apresentou o melhor ajuste entre as curvas analisadas, exceto para a resistência à flexão, cujo melhor ajuste foi a curva exponencial (Tabela II). Em virtude das pequenas diferenças de ajustes entre as curvas analisadas, optou-se por considerar o valor das propriedades para o material sem poros $\left(\mathrm{M}_{0}\right)$ como média dos três ajustes (Tabela II). Os resultados das velocidades sônicas longitudinal, $\mathrm{V}_{\mathrm{L}}$, e transversal, $\mathrm{V}_{\mathrm{T}}$, e do coeficiente de Poisson, $v$, apresentaram parâmetros das curvas ajustadas (b, $b_{1}$ e $b_{2}$, Tabela II) significativamente menores do que os das demais propriedades e, no caso do ajuste polinomial, os parâmetros do termo quadrático $\left(b_{2}\right)$ foram negativos. Estes resultados mostram que a diminuição das propriedades $V_{L}, V_{T}$ e $v$ com a porosidade é menos acentuada do que a diminuição das demais propriedades mecânicas (módulos E, G e K, resistência, $\mathrm{K}_{\mathrm{Ic}}$ e dureza). Rice $[2,7]$ compilou vários dados da literatura de diferentes cerâmicas e observou que o valor de b no ajuste exponencial foi relativamente baixo para o coeficiente $v(1,2 \pm 1,2)$ em relação às propriedades $\mathrm{E}, \mathrm{G}, \mathrm{K}$, resistência e dureza, cujos valores médios variaram entre cerca de 3 e 4 . Os valores de b dos módulos de elasticidade, da resistência e de $\mathrm{K}_{\mathrm{Ic}}$ foram próximos a esta faixa (Tabela II). O valor de b do ajuste exponencial da dureza Vickers foi maior $(5,8)$. Os dados compilados de Rice [7] para a dureza Vickers de aluminas também mostram valores altos de b (5,5 e 6,3), indicando que a influência da porosidade na dureza da alumina é mais acentuada do que nas demais propriedades mecânicas analisadas.

Chang et al. [26] observaram, em uma alumina com até $25 \%$ de porosidade, relação linear entre as velocidades sônicas e a porosidade. Obtiveram valores de b dos resultados 
das velocidades $V_{L}$ e $V_{T}$ de 1,3 e 1,1, respectivamente, e valores médios de $\mathrm{V}_{\mathrm{L} 0}$ de $11513 \mathrm{~m} / \mathrm{s}$ e de $\mathrm{V}_{\mathrm{T} 0}$ de $6645 \mathrm{~m} / \mathrm{s}$, resultados próximos aos observados neste trabalho (Fig. $4 \mathrm{e}$ Tabela II). A velocidade de propagação da onda sônica é uma propriedade importante para comportamentos mecânicos dinâmicos, como impacto balístico [27].

$\mathrm{O}$ efeito da porosidade no coeficiente de Poisson, $v$, foi pouco estudado e compreendido. Os poucos modelos analíticos prevêem desde diminuição, invariância e aumento de $v$ com a porosidade [2]. Kwan et al. [17] estudaram uma alumina preparada com poros abertos com porosidade variando entre $\sim 12 \%$ e $45 \%$ e observaram diminuição de $v$ com o aumento da porosidade. O valor médio de $v_{0}$ obtido foi de 0,244 , próximo ao valor observado neste trabalho (Tabela II). $\mathrm{O}$ valor de $\mathrm{v}_{0}$ calculado a partir de constantes elásticas determinadas em monocristal de alumina é reportado como 0,233 [28]. A compreensão do efeito da porosidade no coeficiente $v$ é importante para os modelamentos analíticos baseados em concentração de tensão. As Eqs. I a N (Tabela I) consideram $v$ invariante com a porosidade. Entretanto, neste trabalho o coeficiente $v$ foi aproximadamente constante somente até a porosidade de $19 \%$ (Fig. 5), o que indica que acima desta porosidade os modelos precisam prever a diminuição do valor de $v$.

Os valores para porosidade zero dos módulos de Young, E, de cisalhamento, $\mathrm{G}$, e volumétrico, $\mathrm{K}$, foram de $421 \pm 18$, $171 \pm 8$ e $269 \pm 17$ GPa, respectivamente (Fig. 6, Tabela II). Os valores de $E_{0}, G_{0}$ e $K_{0}$ calculado a partir de constantes elásticas determinadas em monocristal de alumina são reportados como 402, 163 e 251 GPa, respectivamente [28]. Os dados compilados por Rice [7] de resultados de $E_{0}$ obtidos das curvas ajustadas para cerâmicas de alumina com diferentes faixas de porosidade mostram valores variando entre 280 e $420 \mathrm{GPa}$. Os valores de $\mathrm{E}_{0}$ e $\mathrm{G}_{0}$ obtidos pelo melhor ajuste dos resultados de Kwan et al. [17] em alumina porosa foram de 409,5 e 165,4 GPa, respectivamente. Assim, os resultados dos módulos de elasticidade deste trabalho estão próximos dos valores superiores observados em literatura.

Os valores para porosidade zero da resistência à flexão, $\sigma$, tenacidade à fratura, $\mathrm{K}_{\mathrm{Ic}}$, e dureza Vickers foram de (397 \pm 15) $\mathrm{MPa},(4,03 \pm 0,13) \mathrm{MPa}^{1 / 2}$ e $(19,8 \pm 1,4) \mathrm{GPa}$, respectivamente (Figs. 7 a 9, Tabela II). A literatura apresenta uma larga faixa de valores de $\sigma_{0}$ de cerâmicas de alumina, variando de 280 a quase $900 \mathrm{MPa}$ [7, 17]. Esta grande variação não chega a ser uma surpresa, pois a resistência à flexão varia com as dimensões do espécime, a geometria de carregamento e, principalmente, com o tamanho dos defeitos introduzidos no processamento da cerâmica. O valor de $\mathrm{K}_{\mathrm{Ic} 0}$ que tem sido adotado na literatura para a alumina é de $4 \mathrm{MPa} \cdot \mathrm{m}^{1 / 2}$ [5], valor próximo ao obtido neste trabalho. Ostrowski e Rödel [20], entretanto, observaram valor de $\mathrm{K}_{\text {Iс } 0}$ de cerca de 3,5 MPa.m² para duas diferentes aluminas. Os resultados de $\mathrm{HV}_{0}$ reportados na literatura para a alumina são de 22 e $29 \mathrm{GPa}$ [7], valores superiores ao obtido neste trabalho.

A Fig. 10 apresenta os resultados dos módulos E, G e $\mathrm{K}$ normalizados pelos valores de $\mathrm{E}_{0}, \mathrm{G}_{0}$ e $\mathrm{K}_{0}$ (Tabela II) e as curvas previstas pelos modelos analíticos baseados em concentração de tensão. As curvas foram calculadas por meio das Eqs. I a N (Tabela I), considerando os valores de $E_{0}, G_{0}, K_{0}$ e $v_{0}$ da Tabela II. Quando as equações previram apenas soluções para dois módulos, o terceiro foi calculado pela relação de elasticidade dada por:

$$
E=\frac{9 K G}{3 K+G}
$$

Tabela II - Resultados das curvas linear, polinomial e exponencial ajustadas sobre os valores experimentais. $\mathrm{R}^{2}$ e dp são, respectivamente, o coeficiente de determinação e o desvio-padrão.

[Table II - Results of fitted linear, polynomial, and exponential curves on the experimental values. $R^{2}$ and $d p$ are, respectively, the coefficient of correlation and the standard deviation.]

\begin{tabular}{|c|c|c|c|c|c|c|c|c|c|c|c|c|c|c|}
\hline \multirow[t]{2}{*}{$\mathbf{M}$} & & \multicolumn{3}{|c|}{$M=M_{0}(1-b P)$} & \multicolumn{4}{|c|}{$\mathbf{M}=\mathbf{M}_{0}\left(1-\mathbf{b}_{1} \mathbf{P}+\mathbf{b}_{2} \mathbf{P}^{2}\right)$} & \multicolumn{3}{|c|}{$M=M_{0} \exp (-b P)$} & \multicolumn{3}{|c|}{$M_{0}$ médio } \\
\hline & & $\mathbf{M}_{0}$ & b & $\mathbf{R}^{2}$ & $\mathbf{M}_{0}$ & $\mathbf{b}_{1}$ & $\mathbf{b}_{2}$ & $\mathbf{R}^{2}$ & $\mathbf{M}_{0}$ & $\mathbf{b}$ & $\mathbf{R}^{2}$ & média & & dp \\
\hline $\mathbf{V}_{\mathrm{L}}$ & $(\mathrm{m} / \mathrm{s})$ & 11215 & 1,25 & 0,986 & 11023 & 0,86 & $-1,20$ & 0,992 & 11438 & 1,66 & 0,972 & 11225 & \pm & 208 \\
\hline $\mathbf{V}_{\mathrm{T}}$ & $(\mathrm{m} / \mathrm{s})$ & 6571 & 1,15 & 0,991 & 6483 & 0,85 & $-0,93$ & 0,995 & 6675 & 1,48 & 0,979 & 6576 & \pm & 96 \\
\hline$v$ & & 0,243 & 0,67 & 0,847 & 0,235 & 0,13 & $-2,38$ & 0,921 & 0,244 & 0,78 & 0,845 & 0,241 & \pm & 0,005 \\
\hline $\mathbf{E}$ & (GPa) & 405 & 2,26 & 0,987 & 417 & 2,93 & 2,12 & 0,994 & 440 & 4,08 & 0,988 & 421 & \pm & 18 \\
\hline G & (GPa) & 164 & 2,28 & 0,992 & 168 & 2,78 & 1,59 & 0,996 & 180 & 4,19 & 0,985 & 171 & \pm & 8 \\
\hline $\mathbf{K}$ & (GPa) & 256 & 2,43 & 0,989 & 262 & 2,91 & 1,51 & 0,992 & 289 & 4,87 & 0,975 & 269 & \pm & 17 \\
\hline$\sigma$ & (MPa) & 382 & 2,22 & 0,980 & 397 & 3,03 & 2,58 & 0,993 & 412 & 3,89 & 0,994 & 397 & \pm & 15 \\
\hline $\mathbf{K}_{\text {Ic }}$ & $\left(\right.$ MPa.m $\left.^{1 / 2}\right)$ & 3,93 & 1,98 & 0,985 & 3,99 & 2,33 & 1,08 & 0,988 & 4,18 & 3,26 & 0,971 & 4,03 & \pm & 0,13 \\
\hline $\mathrm{HV}_{1}$ & (GPa) & 18,5 & 2,66 & 0,977 & 19,6 & 3,93 & 4,10 & 0,997 & 21,3 & 5,82 & 0,990 & 19,8 & \pm & 1,4 \\
\hline
\end{tabular}


No caso da equação de Mackenzie (Eq. J), os termos de segunda ordem foram desprezados. Procedimento similar foi adotado por Rice [2], pois estes termos só apresentam influência significativa em altas frações de poros, na faixa que o modelo não se aplica.

Aequação de Hashin-Rosen (Eq. N), para corpos contendo

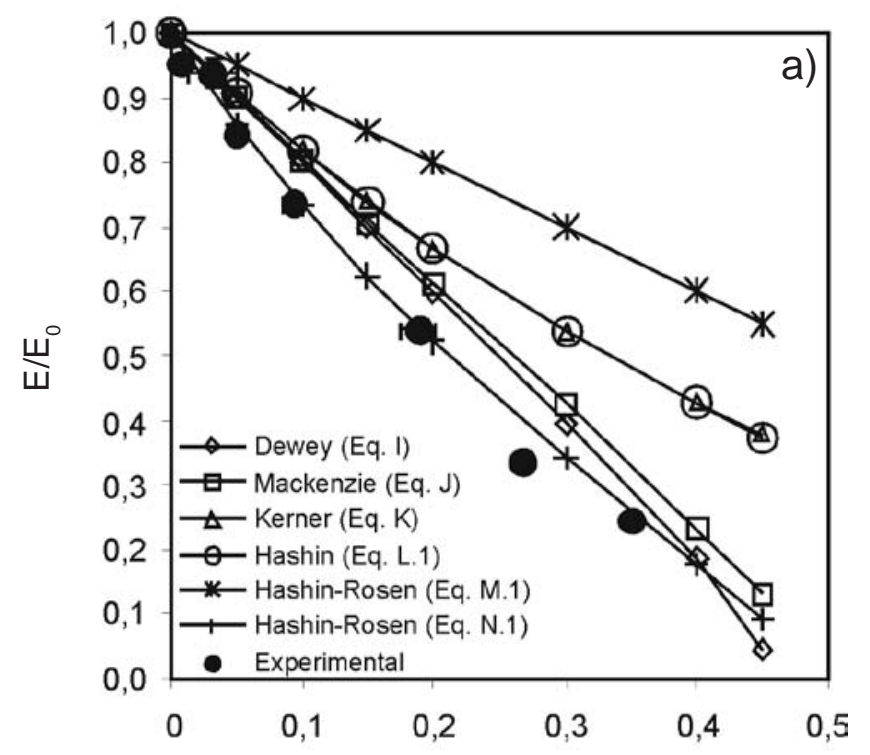

Fração volumétrica de poros poros cilíndricos alinhados solicitados perpendicularmente ao eixo do poro, apresentou bons ajustes sobre os resultados experimentais dos módulos E (Fig. 10a) e G (Fig. 10b) em toda a faixa de poros investigada. As equações de Dewey (Eq. I) e Mackenzie (Eq. J) apresentaram curvas próximas, mas um pouco superiores, aos valores experimentais de E

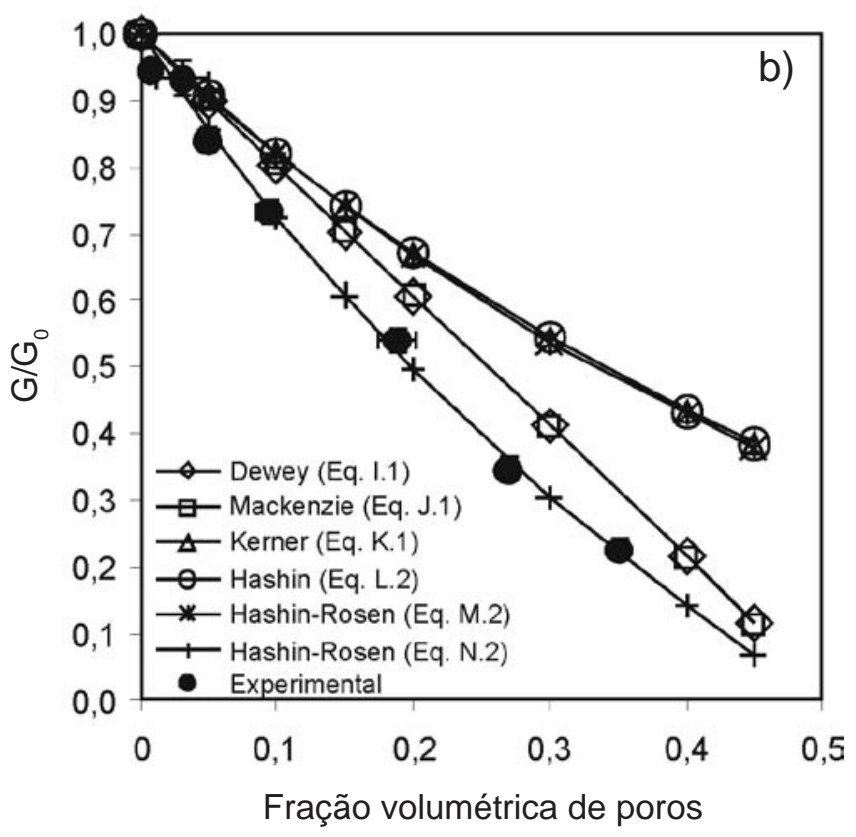

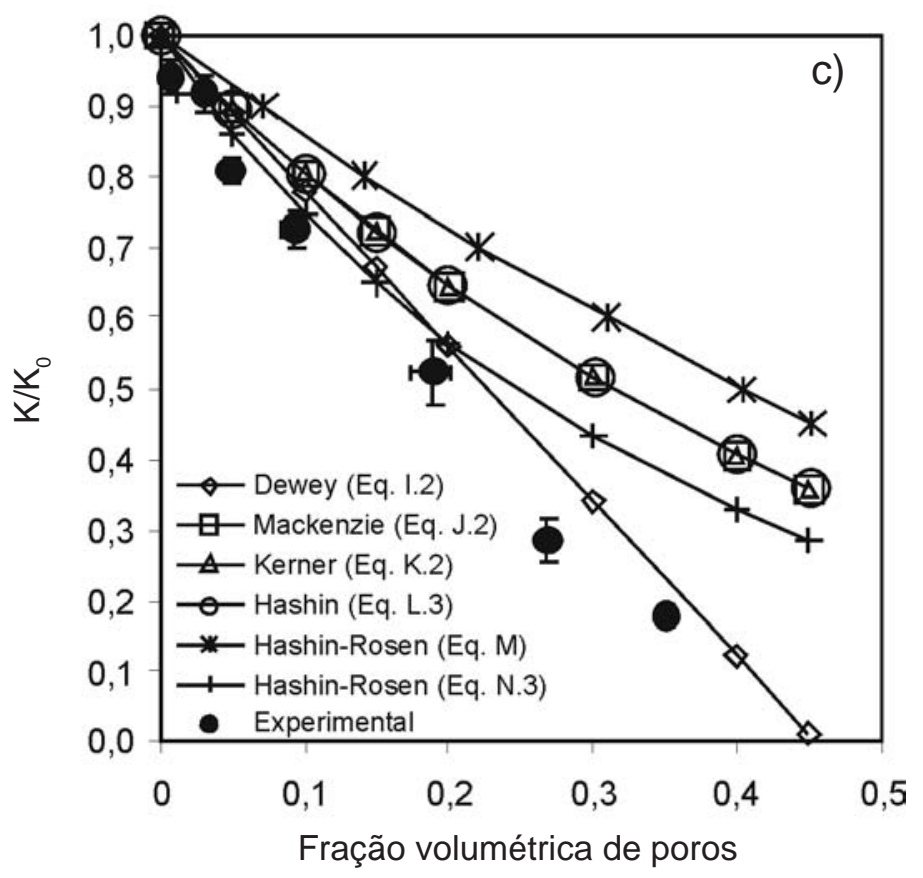

Figura 10: Módulos de elasticidade relativos em função da porosidade: (a) módulo de Young, (b) módulo de cisalhamento e (c) módulo volumétrico. As curvas representam os modelos analíticos baseados em concentração de tensão.

[Figure 10: Relative elastic moduli versus porosity: (a) Young's modulus, (b) shear modulus, and (c) bulk modulus. The curves show analytical models based on stress concentration.] 
e G. Para o módulo K, a equação de Hashin-Rosen (Eq. N) apresentou bom ajuste até a porosidade de cerca de $20 \%$, mas acima deste valor passou a apresentar valores maiores do que os experimentais (Fig. 10c). A equação de Dewey (Eq. I) apresentou a melhor tendência de decaimento de K em toda a faixa de porosidade dos resultados experimentais, mas os valores previstos foram um pouco superiores aos resultados experimentais (Fig. 10c). As equações de Kerner (Eq. K), Hashin (Eq. L) e Hashin-Rosen, para poros cilíndricos alinhados e solicitados transversalmente (Eq. M), para os três módulos e a de Mackenzie para o módulo K (Eq. J.2) apresentaram resultados muito superiores aos obtidos experimentalmente.

Phani [6] considera que os modelos analíticos baseados em poros esféricos não se ajustam bem aos dados experimentais de propriedades elásticas e que os modelos que consideram os poros não esféricos, como poros cilíndricos, orientados perpendicularmente à tensão aplicada, resultam em melhores aproximações. Neste trabalho, a equação de Hashin-Rosen nesta condição de solicitação (Eq. N) foi a que melhor se ajustou aos resultados experimentais, o que indica que o material ensaiado apresentava idealisticamente poros com forma cilíndrica alinhados perpendicularmente à solicitação. Como o método de preparação dos corpos-verdes foi prensagem uniaxial, existe a possibilidade de que tenha ocorrido alinhamento das partículas (e, portanto, dos poros) na seção transversal à direção de prensagem. $\mathrm{O}$ alinhamento pode ser tanto dos poros entre partículas (poros finos) como dos poros entre grânulos (poros grandes). Caso, durante a sinterização, nos estágios inicial e intermediário, os canais dos poros abertos se formarem preferencialmente seguindo o alinhamento das partículas, proveniente da conformação, poderia se formar uma estrutura de poros que se aproxima da prevista pelo modelo de Hashin-Rosen (Eq. N). Esta hipótese, entretanto, necessita de comprovação experimental que indique que há anisotropia de resposta elástica no corpo, pela determinação das constantes elásticas principalmente na direção paralela à maior dimensão da barra, ortogonal à direção de prensagem, e a comprovação de alinhamento dos poros, por ex., por análise microestrutural quantitativa nas três seções ortogonais da amostra.

A Fig. 11 apresenta os valores de todas as propriedades mecânicas normalizados pelos respectivos valores determinados para a alumina sem poros (Tabela II), em escala logarítmica, em função da porosidade. Nesta figura, também foram plotadas em linhas tracejadas as curvas dos modelos de área sólida mínima (ASM, Fig. 1). Observou-se que, em geral, com o aumento da porosidade, inicialmente os valores das propriedades relativas diminuíram aproximadamente linearmente com uma dada inclinação até a porosidade de 19\%. Os valores do parâmetro b da equação exponencial (Eq. C), que é a inclinação da curva exponencial no gráfico semi-log, nesta faixa inicial de porosidade, foram para as velocidades sônicas $\left(\mathrm{V}_{\mathrm{L}}\right.$ e $\left.\mathrm{V}_{\mathrm{T}}\right)$ ao redor de 1 , para os módulos de elasticidade $(\mathrm{E}, \mathrm{G}$ e $\mathrm{K})$, a resistência à flexão $(\sigma)$

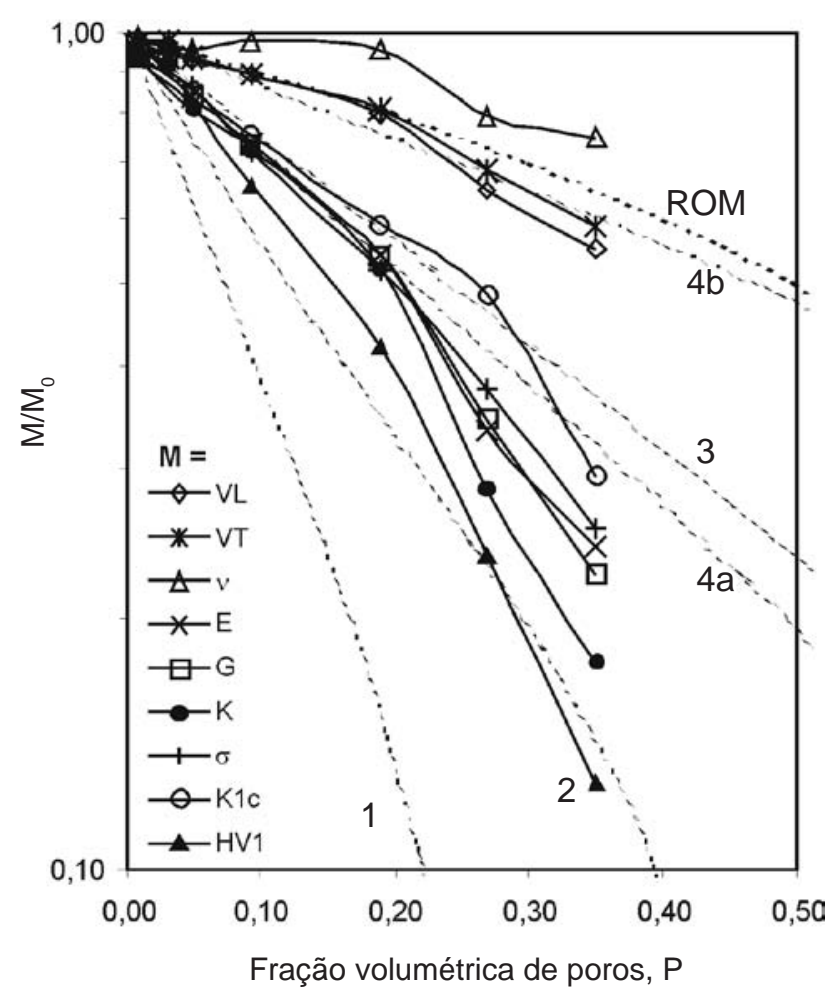

Figura 11: Propriedades relativas (velocidades sônicas, $V_{L}$ e $\mathrm{V}_{\mathrm{T}}$, coeficiente de Poisson, v, módulos de elasticidade, E, G e K, resistência à flexão, $\sigma$, tenacidade à fratura, $\mathrm{K}_{\mathrm{Ic}}$, e dureza Vickers, $\mathrm{HV}_{1}$ ) em função da porosidade. As curvas tracejadas indicadas com números referem-se aos modelos de área sólida mínima: 1 - partículas esféricas em empilhamento romboédrico; 2 - partículas esféricas em empilhamento cúbico; 3 - poros esféricos em empilhamento cúbico; 4a - poros cilíndricos em empilhamento cúbico alinhados transversalmente à tensão aplicada; $4 \mathrm{~b}$ - poros cilíndricos em empilhamento cúbico alinhados paralelamente à tensão aplicada. A curva tracejada indicada com ROM é a regra das misturas.

[Figure 11: Relative properties (sonic velocities, $V_{L}$ and $V_{T}$, Poisson's ratio, $v$, elastic moduli, $E, G$, and $K$, flexural strength, $\sigma$, fracture toughness, $K_{\mathrm{I}}$, and Vickers hardness, $H V_{1}$ ) versus porosity. Dashed curves indicated by numbers are minimum solid area models: 1 spherical particles in rhombohedral stacking; 2 - spherical particles in cubic stacking; 3 - spherical pores in cubic stacking; 4 a - cylindrical pores in cubic stacking aligned transversal to applied stress; $4 b$ cylindrical pores in cubic stacking aligned parallel to applied stress. The dashed curve indicated by ROM is rule of mixture.]

e a tenacidade à fratura $\left(\mathrm{K}_{\mathrm{IC}}\right)$ ao redor de 3 e para a dureza Vickers (HV) entre 4 e 5 . Acima de 19\% de fração de poros, as propriedades apresentaram, em geral, diminuição mais acentuada em relação à trajetória inicial, i.e., ocorreu um aumento de inclinação da curva exponencial. Exceção foi a tenacidade à fratura, cuja transição foi observada na passagem de $\sim 27 \%$ para $35 \%$ de porosidade. A dureza HV parece ter apresentado uma segunda transição na passagem de $5 \%$ para 9\% de porosidade. Cada modelo de área sólida mínima (ASM) prevê mudanças de inclinação principalmente na 
faixa de porosidade que se aproxima do limite de percolação (porosidade crítica) das partículas (Fig. 1). Entretanto, nas faixas de porosidade e propriedade relativa apresentadas na Fig. 11 ( 0 a $50 \%$ e 0,1 a 1 , respectivamente), os modelos de ASM (linhas tracejadas) prevêem, em geral, pequenas mudanças de inclinação. As mudanças de inclinação observadas, em geral, a partir de $19 \%$, podem indicar mudança na estrutura dos poros e das partículas. Na região entre dois modelos de ASM, valores intermediários podem indicar mistura de dois (ou mais) tipos de arranjo de poros [1]. A presença de uma mistura de tipos de arranjos de poros é de se esperar em amostras parcialmente sinterizadas, pois a evolução microestrutural durante a sinterização ocorre com mudança gradativa de poros abertos (alongados) para poros fechados, que tendem a uma forma isométrica. Assim, as mudanças de inclinação podem indicar mudança de predominância de um determinado arranjo de poros ou partículas.

Os resultados plotados na Fig. 11 apresentam duas tendências principais. A primeira está relacionada com as velocidades sônicas $\left(V_{L}\right.$ e $\left.V_{T}\right)$ que apresentaram resultados próximos ao previsto pela regra das misturas (curva tracejada indicada com ROM na Fig. 11) até 19\% de porosidade. Isto pode indicar que as velocidades sônicas variam com a massa do corpo (i.e., com a fração volumétrica, ou fração em área média da seção, da parte sólida). Como as propriedades que seguem a regra das misturas com a porosidade não são sensíveis às características dos arranjos dos poros [7], os desvios observados acima de $19 \%$ de porosidade podem indicar que a regra das misturas seja um modelo simplificado para descrever o efeito da porosidade na velocidade sônica. Rice [1] considera que, em decorrência da sua relação quadrática com o módulo de elasticidade, o valor de b (inclinação) da curva exponencial é simplesmente a metade do valor de b do módulo. Esta relação, entretanto, não foi observada até a porosidade de $19 \%$, onde a relação entre os valores de b das velocidades sônicas e dos módulos de elasticidade foi de cerca de 1/3 (Fig. 11).

A segunda tendência está relacionada com as propriedades de módulos de elasticidade ( $\mathrm{E}, \mathrm{G}$ e $\mathrm{K}$ ), resistência à flexão $(\sigma)$ e tenacidade à fratura $\left(\mathrm{K}_{\mathrm{IC}}\right)$. Os valores de $\mathrm{E}, \mathrm{G}, \mathrm{K}$ e $\sigma$, até $19 \%$ de porosidade, seguiram o modelo de ASM de poros cilíndricos em empilhamento cúbico alinhados transversalmente à tensão aplicada (curva tracejada indicada com 4a na Fig. 11). O mesmo tipo de arranjo previsto pelo modelo de Hashin-Rosen (Eq. N, Fig. 10). Acima de 19\%, os resultados desviaram deste modelo de ASM. Os valores de $\mathrm{K}_{\mathrm{Ic}}$ se aproximaram mais do modelo de ASM de poros esféricos em empilhamento cúbico (curva tracejada indicada com 3 na Fig. 11) até a porosidade de $27 \%$. Rice [1] tem associado às propriedades de cerâmicas sinterizadas, que decaem com inclinação $b$ de $\sim 3$ para a faixa inicial de porosidade, com o modelo de poros esféricos, sendo que o desvio em relação a este modelo em maiores porosidades é associado com a participação do modelo de partículas esféricas em empilhamento cúbico (curva tracejada indicada com 2 na Fig.
11). Rice [1] também considera que as distribuições aleatórias de poros esféricos ou partículas esféricas são similares aos respectivos empilhamentos cúbicos. Os resultados de E, G, K, $\sigma \mathrm{e} \mathrm{K}_{\mathrm{Ic}}$ podem também ser associados às misturas dos modelos de ASM de empilhamento cúbico de poros esféricos e de empilhamento cúbico de partículas esféricas, sendo que até 19\% de porosidade, o primeiro modelo prevalece em relação ao segundo. Esta interpretação é reforçada por dois aspectos: i) na faixa de alta porosidade (nos estágios inicial e intermediário da sinterização), os poros apresentam-se abertos e podem ser aproximados com poros cilíndricos, mas é exatamente nesta faixa que os resultados de E, G, K e $\sigma$ se desviam do modelo de poros cilíndricos alinhados transversalmente à tensão aplicada; ii) as análises microestruturais não indicaram presença de poros com morfologia alongada, que poderiam se aproximar de poros cilíndricos.

Desvio da tendência dos resultados acima expostos foi apresentado pela dureza $\mathrm{HV}$, que a partir de $5 \%$ de porosidade apresentou diminuição mais acentuada em relação ao módulo de Young e à resistência à flexão, sendo que a diferença aumentou com o aumento da porosidade (Fig. 11). Este resultado sugere que, além do efeito da porosidade, há um outro efeito que é intensificado pela porosidade. Rice [7] sugere que um processo de dano cumulativo, como ocorre na resistência à compressão, possa explicar a maior dependência da dureza (e da resistência à compressão) com a porosidade. Ele comenta, entretanto, que há poucos resultados disponíveis para confirmar esta sugestão [7]. Os resultados deste trabalho também sugerem a ocorrência de um processo de dano, que pode ser a formação de microtrincas na região da zona de deformação plástica da indentação, e/ou região adjacente. Nos corpos parcialmente sinterizados, quanto maior a porosidade, maior é o espaço para movimentação das partículas, o que deve proporcionar maior deflexão das ligações entre as partículas (pescoços) durante a indentação. Assim, o aumento da porosidade pode favorecer o rompimento dos pescoços, gerando maior número de microtrincas, o que pode causar um efeito de "amolecimento" ou diminuição da rigidez local, na região à frente da indentação.

A mudança de inclinação das propriedades acima da porosidade de $19 \%$ coincide com a diminuição do coeficiente de Poisson (Fig. 11). Este resultado pode sugerir que o coeficiente de Poisson é sensível à mudança de estrutura dos poros.

\section{CONCLUSÕES}

Em geral, as propriedades mecânicas avaliadas diminuíram com o aumento da porosidade na faixa de $0,8 \%$ a $35 \%$, sendo que a diminuição foi menos acentuada nas velocidades sônicas e mais acentuada na dureza. O coeficiente de Poisson manteve-se aproximadamente constante até a porosidade de $19 \%$; acima deste valor ele diminuiu. Dentre as equações empíricas avaliadas (linear, polinomial e exponencial), a de polinômio do $2^{\circ}$ grau apresentou os melhores ajustes, com exceção da resistência 
à flexão, cujo melhor ajuste foi a exponencial. As diferenças entre os ajustes foram, entretanto, pequenas.

Os valores das propriedades da alumina para porosidade zero, determinados pela média dos três ajustes, foram: velocidade sônica longitudinal, $V_{L}(11225 \pm 208) \mathrm{m} /$ s; velocidade sônica transversal, $\mathrm{V}_{\mathrm{T}}(6576 \pm 96) \mathrm{m} / \mathrm{s}$; coeficiente de Poisson, $v(0,241 \pm 0,005)$; módulo de Young, E $(421 \pm 18) \mathrm{GPa}$; módulo de cisalhamento, G (171 \pm 8) GPa; módulo volumétrico, K (269 \pm 17$)$ GPa; resistência à flexão em quatro pontos, $\sigma(397 \pm 15) \mathrm{MPa}$; tenacidade à fratura, $\mathrm{K}_{\mathrm{Ic}}(4,03 \pm 0,13) \mathrm{MPa} \cdot \mathrm{m}^{1 / 2}$; e dureza Vickers, $\mathrm{HV}_{1}$ $(19,8 \pm 1,4) \mathrm{GPa}$.

O modelo analítico baseado em concentração de tensão que melhor se ajustou aos resultados dos módulos E e G foi o de Hashin-Rosen para configuração de poros cilíndricos alinhados transversalmente à aplicação da tensão.

A análise pelos modelos de área sólida mínima dos resultados de $\mathrm{E}, \mathrm{G}, \mathrm{K}, \sigma$ e $\mathrm{K}_{\mathrm{Ic}}$, que apresentaram tendências similares com a porosidade, indicou que, até $19 \%$ de porosidade, o modelo de poros esféricos em arranjo cúbico foi predominante e, acima desta porosidade, atuou também o modelo de partículas esféricas em arranjo cúbico. A maior dependência da dureza HV com a porosidade indicou que, além do efeito da área sólida mínima, há um efeito de dano, possivelmente de microtrincas, que é intensificado pela porosidade.

\section{REFERÊNCIAS}

[1] R. W. Rice, J. Mater. Sci. 31 (1996) 102.

[2] R. W. Rice, in Treatise on Materials Science and Technology, Vol. 11, Ed. R. K. MacCrone, Academic Press, New York (1977) 199-381.

[3] E. A. Dean, J. A. Lopez, J. Am. Ceram. Soc. 66 (1983) 366.

[4] K. K. Phani, S. K. Niyogi, J. Mater. Sci. 22 (1987) 257.

[5] D. C. C. Lam, F. F. Lange, A. G. Evans, J. Am. Ceram. Soc. 77, 8 (1994) 2113.

[6] K. K. Phani, J. Mater. Sci. 31 (1996) 262.

[7] R. W. Rice, J. Mater. Sci. 31 (1996) 1509.
[8] K. K. Phani, S. K. Niyogi, J. Am. Ceram. Soc. 70 (1987) C-362.

[9] S. C. Nanjangud, R. Brezny, D. J. Green, J. Am. Ceram. Soc. 78 (1995) 266.

[10] R. W. Rice, J. Mater. Sci. 28 (1993) 2187.

[11] R. W. Rice, J. Mater. Sci. 32 (1997) 4731.

[12] F. P. Knudsen, J. Am. Ceram. Soc. 45 (1962) 94.

[13] R. M. Spriggs, J. Am. Ceram. Soc. 44 (1961) 628.

[14] F. P. Knudsen, J. Am. Ceram. Soc. 42 (1959) 376.

[15] R. L. Coble, W. D. Kingery, J. Am. Ceram. Soc. 39 (1956) 377.

[16] B. D. Flinn, R. K. Bordia, A. Zimmermann, J. Rödel, J. Eur. Ceram. Soc. 20 (2000) 2561.

[17] Y. B. P. Kwan, D. J. Stephenson, J. R. Alcock, J. Mater. Sci. 35 (2000) 1205.

[18] D. R. Biswas, R. M. Fulrath, Trans. J. Brit. Ceram. Soc. 79 (1980) 1.

[19] T. Ostrowski, A. Ziegler, R. K. Bordia, J. Rödel, J. Am. Ceram. Soc. 81 (1998) 1852.

[20] T. Ostrowski, J. Rödel, J. Am. Ceram. Soc. 82 (1999) 3080.

[21] ASTM. Standard Test Method for Flexural Strength of Advanced Ceramics at Ambient Temperature, ASTM C 1161 (2002) 15 p.

[22] JIS. Testing Methods for Elastic Modulus of High Performance Ceramics, JIS R 1602 (1986) p. 216.

[23] ASTM. Standard Test Method for Determination of Fracture Toughness of Advanced Ceramics at Ambient Temperature, ASTM C 1421-01b (2001) 33 p.

[24] R. L. Coble, J. Am. Ceram. Soc. 45 (1962) 123.

[25] H. N. Yoshimura, A. C. da Cruz, Y. Zhou, H. Tanaka, J. Mater. Sci. 37 (2002) 1541.

[26] L.-S. Chang, T.-H. Chuang, W. J. Wei, Mater. Charact. 45 (2000) 221.

[27] E. Medvendovski, Am. Ceram. Soc. Bull. 81 (2002) 27.

[28] D. J. Green, An Introduction to the Mechanical Properties of Ceramics, Cambridge University Press, Cambridge (1998) p. 25.

(Rec. 01/07/2004, Ac. 04/02/2005) 